\title{
Efficacy and Potential MicroRNA Mechanism for Computed Tomography-Guided Percutaneous Radiofrequency Ablation of Primary Lung Cancer and Lung Metastasis from Liver Cancer
}

\author{
Xun $\mathrm{Hu}^{\mathrm{a}, \mathrm{b}}$ Fan Zhang ${ }^{\mathrm{a}}$ Xiao-Rong Liu ${ }^{\mathrm{a}}$ Yun-Tao $\mathrm{Wu}^{\mathrm{a}} \quad$ Yi-Ming Ni \\ aDepartment of Thoracic and Cardiovascular Surgery, Second Hospital of Jiaxing, Jiaxing, \\ ${ }^{b}$ Department of Thoracic and Cardiovascular Surgery, First Affiliated Hospital, Zhejiang University \\ School of Medicine, Hangzhou, China
}

\section{Key Words}

Lung cancer • Non-small cell lung cancer (NSCLC) • Lung metastasis • Computed tomographyguided percutaneous radiofrequency ablation (CT-PRFA) $\cdot$ miRNAs $\bullet$ Let-7 $\bullet$ miR-126 $\bullet$ miR-34

\begin{abstract}
Background: The aim of this study was to evaluate comparatively the effectiveness of computed tomography-guided percutaneous radiofrequency ablation (CT-PRFA) for primary non-small cell lung cancer (NSCLC) and lung metastases from hepatocellular carcinoma (HCC) and to explore the potential miRNA mechanisms for the efficacy of CT-PRFA. Methods: 14 patients pathologically diagnosed with NSCLC and 12 patients with lung metastases from HCC were enrolled in the study and underwent CT-PRFA. Clinical outcomes were compiled on the basis of review of medical records, imaging follow-up reports, and any biopsy-proved residual or recurrent disease. Real-time RT-PCR was used to quantify the selected miRNAs known to be play key roles in lung cancer. Results: A total of 21 tumors were treated with umbrella-tip electrodes and spiral-tip electrodes were used for the remaining 8 tumors. The median followup was 13.5 months (range, 3-30 months) and no patient was lost to follow-up. The rate of technique efficacy for primary tumors was 93\% (13 of 14). Treatment was successful in 11 out of $12(91.7 \%)$ lung metastases patients. Overall survival rate was $80.8 \%$ at 2 years, and cancer-specific survival rate was $100 \%$ at 2 years. The tumor-free survival was $69.2 \%$ at 1 year and $26.9 \%$ at 2 years. Before PRFA, tumor suppressor let-7a and miR-34a were downregulated whereas oncomiR miR-21 was upregulated in primary tumors, and let-7a and miR-126 levels were downregulated whereas oncomiRs miR-21, miR-155 and miR-17-5p/miR-20b levels


were upregulated in secondary tumors. This abnormal expression was normalized by CT-PRFA. Most notably, CT-PRFA failed to normalize the deregulated miRNAs in the non-survivors. Conclusions: CT-PRFA is a effective treatment for primary NSCLCs and secondary lung tumors from HCC and the efficacy may be related to its ability to normalize deregulated expression of miRNAs: upregulating tumor suppressor miRNAs and downregulating oncomiRs.

Copyright $@ 2014$ S. Karger AG, Basel

\section{Introduction}

Lung cancer, among the most frequently occurring malignancies, is the leading cause of cancer-related death in the world [1]. Lung cancer patients with advanced non-small-cell lung carcinoma (NSCLC) have a median survival time of six to eight months and a 1-year survival rate of only 10-20\% [2]. Moreover, lung is a frequent site for metastasis, and pulmonary metastases occur in $30 \%$ of all malignancies. Surgical resection, the gold standard therapy, is the treatment of choice for primary NSCLCs and isolated pulmonary metastases from other cancers $[3,4]$. However, when the initial diagnosis is made, $\sim 65 \%$ of all NSCLC patients are ineligible for curative resection due to a variety of associated complications [5, 6]. Unfortunately, systemic chemotherapy and radiation therapy have failed to yield drastic improvement of outcomes in patients with unresectable disease, and increased efficacy is often in the face of unacceptable toxicity, especially for patients with comorbid conditions $[7,8]$.

Percutaneous radiofrequency ablation under computed tomography (CT) guidance (CTPRFA), a minimally invasive therapeutic approach, has been applied over a decade to the treatment of primary and secondary liver tumors $[9,10]$ with impressive and promising therapeutic outcomes. This approach has also been recently evaluated for its applicability to both primary and metastatic malignant lung tumors [11-18]. In principle, pulmonary CT-PRFA is believed to be a safe and feasible technique for the treatment of human lung cancer, although some contradictory results exist in these studies because of the small and heterogeneous patient groups involve in the studies, together with differences in the CTPRFA protocols used in the various studies. More studies are definitely required to confirm the effectiveness of CT-PRFA and to clarify the unresolved issues. A number of studies have addressed the efficacy of CT-PRFA in treating pulmonary metastases from colorectal cancer and renal cell carcinoma. During the course of the present study, one case report [19] and two retrospective studies $[20,21]$ have reported the efficacy of CT-PRFA therapy of pulmonary metastases from hepatocellular carcinoma.

Over the past decade, numerous studies have been published showing the critical involvement of microRNAs (miRNAs or miRs) in various types of lung cancers as causal factors, regulators, risk stratification molecules, diagnostic biomarkers, etc [22-40]. miRNAs regulate expression of their target genes/mRNAs through seed site (the $5^{\prime}$ end 2-8 nucleotides) base pairing to the sequence motif(s) in the 3' untranslated region (3' UTR) of the target mRNA. In this way, miRNAs primarily produce post-transcriptional repression of the genes. Deregulation of miRNAs can result in abnormal or adverse changes of gene expression: upregulation of miRNAs leads to downregulation of their targeted genes whereas or downregulation of miRNAs can cause upregulation of genes due to relief of the tonic repression under normal situations. It has been shown that certain miRNAs are deregulated in NSCLCs contributing to the pathological process. A number of studies have demonstrated the crucial role of let-7 family members as tumor suppressor miRNAs in lung cancer [22-28]. For example, Yanaihara et al. [26] reported that low let-7a-2 expression correlated with poor overall survival in lung cancer patients. Yu et al. [27] identified a five-miRNA signature (let7a, miR-137, miR-372, miR-182*, and miR-221) that correlated with disease-free survival in a cohort of 122 NSCLC patients with let-7a as protective miRNA. An independent study of 143 cases of resected lung tumors also showed significantly shorter survival in patients 
with reduced let-7a expression, regardless of disease stage [28]. Similarly, miR-126 has also been shown to be an anti-lung cancer miRNA and be downregulated in lung tumor tissues [29-31]. Another frequently referred tumor suppressor miRNA for lung cancer is the miR34 family [32-35]. It is found to be downregulated in tumor compared with normal tissue likely due to DNA hypermethylation, and low levels of miR-34a expression is correlated with a high probability of recurrence, and is associated with poor overall survival and diseasefree survival [32]. Most intriguingly, miR-34 downregulation is also correlated with a high probability of relapse in surgically resected non-small-cell lung cancer. On the other hand, high expression of miR-155, miR-21, and miR-17-92 cluster correlated with a poor overall survival and stage in lung cancer patients [36-40]. However, whether these miRNAs play a role in the efficacy of CT-PRFA therapy of lung cancer remained unexplored.

Here we present comparative data on the application of CT-PRFA to primary lung cancer and pulmonary metastasis from liver cancer and the associated expression alterations of a set of selected miRNAs known to play key roles in lung cancer. Our primary goal was to examine the efficacy of CT-PRFA with the primary endpoint was the evaluation of the midterm survival rates and recurrence of the malignancy and the potential miRNA mechanism for the therapy.

\section{Materials and Methods}

\section{Patients}

Between January 2008 and October 2010, 26 patients with NSCLCs or metastasis were enrolled in the study and scheduled for CT-PRFA. The study protocol, which was fully concordant with the in accordance with the ethical principles of the Helsinki Declaration, was approved by the Institutional Ethics Committee (Zhejiang University School of Medicine, China). Written informed consent was provided by all participants. All 26 patients had been evaluated jointly by the anesthesiology and surgical staff of the Department of Thoracic and Cardiovascular Surgery, the First Affiliated Hospital, Zhejiang University School of Medicine. In all cases, the patients' tumors were considered unresectable from an anatomic point of view due to unacceptably high surgical risk, or insufficient respiratory reserve on the basis of clinical evaluation, results of respiratory test, or additional comorbidities.

The enrolment criteria included: only patients with NSCLC or pulmonary metastasis from HCC, confirmed by pathological diagnosis; maximum tumor diameter $\leq 3.5 \mathrm{~cm}$; number of tumor nodules $\leq 2$; tumor surrounded by aerated parenchyma; and exclusion of surgery as a treatment option [41]. The exclusion criteria included: tumor infiltration of the mainstem bronchi, trachea and/or mediastinum; NSCLC patients stage II-IV; extrapulmonary spread; active extrapulmonary disease; platelet count $\leq 50,000$ $\mathrm{mm}^{3}$ and/or prothrombin time $\leq 50 \%$; and concomitant disease with life expectancy $<6$ months.

Intrathoracic disease extension was assessed by full-chest spiral computed tomography (CT; Sensation 16; Siemens, Erlangen, Germany). Scans were obtained prior to and $90 \mathrm{~s}$ following power injection of 100$120 \mathrm{~mL}$ contrast medium at a rate of $2 \mathrm{~mL} / \mathrm{s}$. Characteristics of tumors, their vertical, sagittal and traverse diameters, as well as their locations were evaluated in multiplanar images (1-mm scan collimation; 5-mmthick sections; $120 \mathrm{Kvp} ; 190 \mathrm{mAs})$. CT images were visualized using soft-tissue ( $300 \mathrm{~W} / 50 \mathrm{M})$ and lung (1700 $\mathrm{W} /-700 \mathrm{M}$ ) windows. Tumor diagnosis was confirmed by CT-guided aspiration biopsy performed with a 22-gauge needle, and the samples were processed by standard cytology and immunohistochemical staining methods. Tumor-staging was performed by routine hematology, renal and liver-function tests, stool assays for occult blood, and sonographical and spiral CT studies of the abdomen, using the international system [42]. Pulmonary function was assessed by spirometry and blood-gas analysis, and classified according to the Global Initiative for Chronic Obstructive Lung Disease (GOLD) guidelines [43].

Procedure

The whole procedure described by Dupuy et al. [11] and Rossi et al. [41] was employed in our study. The RF system consisted of a generator, an active electrode and grounding pads. The CT-PRFA procedure was performed after an overnight fasting, using a 22-gauge monopolar cooled electrode needle (Cooled-tip $\mathrm{RF}$ system, Radionics), with lengths ranging between 10 and $15 \mathrm{~cm}$ (depending on the depth of the lesion to be treated) with the noninsulated portion of the needle being between 1 and $3 \mathrm{~cm}$. The needle was passed 
through the chest wall and advanced towards the tumour along the pathway that would be used for the electrode insertion. The needle size was set greater than the area to be treated and the active electrodes used were capable of creating thermal lesions measuring 3.0-3.5 cm in diameter. The RF generator was started and power was progressively increased until impedance reached values that blocked further energy delivery. The wattage-current setting was selected automatically by the system and the system adjusts itself according to the level of resistance and impedance. A maximum treatment time was set to $12 \mathrm{~min}$. Long periods (30-40 sec) of inactivity by the machine and short periods $(5-7 \mathrm{sec})$ of activity indicated that the scheduled volume of the nodule had been ablated. Grounding pads $(22 \times 19 \mathrm{~cm})$ were placed in the lumbar (for nodules close to the apex of the lung) or gluteal region (for nodules close to the base), according to the position of the nodule to be treated. Contiguously reconstructed sections (pitch of 1:1) were obtained through the thorax in a single breath hold with 5-mm collimation, without injection of contrast medium. All procedures were performed by using general anesthesia with intubation, and anesthesiologists were in attendance during the procedure. Antibiotic prophylaxis of amoxicillin clavulanate at a dose of $2 \mathrm{~g} /$ day and ofloxacine at a dose of $400 \mathrm{mg}$ /day was started immediately before the procedure and continued through the third post-operative day. Two to four grounding pads were attached to the patient's back and connected to the RF 3000 generator with an initial power of $20 \mathrm{~W}$. To obtain the shortest path to the tumor that did not intersect any major airways or blood vessels, the patient was then prepped in the prone, lateral, or supine decubitus position, depending on the preselected electrode insertion tract. When more than one tumor was present, every effort was made to treat all tumor locations in a single session, as long as no major complication occurred and the patient remained stable during the procedure. Throughout the procedure, heart rate, blood pressure, ECG and blood oxygen levels were continuously monitored.

\section{Immediate post-treatment and follow-up studies}

We followed the procedures described by Dupuy et al. [11] and Rossi et al. [41] for our follow-up studies. Spiral CT was performed at the end of the CT-PRFA procedure for gross assessment of results and the detection of possible complications. The true assessment of the completeness of treatment was based on findings from a second spiral CT repeated 30 days later. Partial ablation was defined as any increase in the size of the ablation zone of more than $20 \%$ in the largest diameter between two follow-up CT scans. The presence of a nonenhancing area larger than the treated one at the tumor site was considered successful treatment with radiological evidence for complete tumor necrosis. In the former case, CT-PRFA was repeated, as described previously, $\sim 1$ week after the residual tumor was detected. If enhancing tissue at the tumor site was observed 30 days after the second CT-PRFA session, the case was defined as a treatment failure. The patients whose 30 day CT scan findings were suggestive of complete tumor necrosis underwent clinical-radiological follow-up that included spiral CT scans 3, 6 and 12 months after CT-PRFA for the first year and every 6 months thereafter.

Mortality rates were calculated, as well as the frequencies of local recurrence (reappearance of enhancing tissue at the original tumor site), intrapulmonary disease progression (appearance of new lung tumors at sites other than the treated one), and extrapulmonary spread.

\section{Real-time reverse transcription-polymerase chain reaction (RT-PCR) quantification of miRNAs}

CT-guided fine needle aspiration biopsy from the area immediately surrounding the site of tumor ablation was performed before PRFA, and 2-week tumor-free survivors after PRFA, 2-year tumor-free survivors after PRFA, and 2-year non-survivors after PRFA during follow-up. For all non-survivors, the biopsies obtained the last time before they deceased were used. The area immediately surrounding the site of tumor ablation was used because the living tissue adjacent to the tumor can provide more meaningful and pertinent data with implications in therapeutic efficacy and the potential of tumor recurrence after RFA. The samples were used for total RNA extraction. MiRNA levels were quantified using the TaqMan quantitative real-time PCR (qRT-PCR) method (10 ng/assay), and quantified with the StepOnePlus ${ }^{\text {TM }}$ Real-Time PCR System (Applied Biosystems, Life Technologies). Taqman Primer assays for miRNAs and the reagents for reverse transcriptase and qRT-PCR reactions were obtained from Applied Biosystems. Relative expression was calculated using the comparative cycle threshold $(\mathrm{Ct})$ method $\left({ }^{2-\Delta \Delta} \mathrm{Ct}\right)$. MiRNA levels were normalized to U6 RNA for inter-well variation and to GAPDH for inter-RNA sample variations. 
Table 1. Patient characterization at enrollment. Data are presented as n (\%) unless otherwise stated. NSCLC: non-small cell lung cancer; GOLD: Global Initiative for Chronic Obstructive Pulmonary Disease

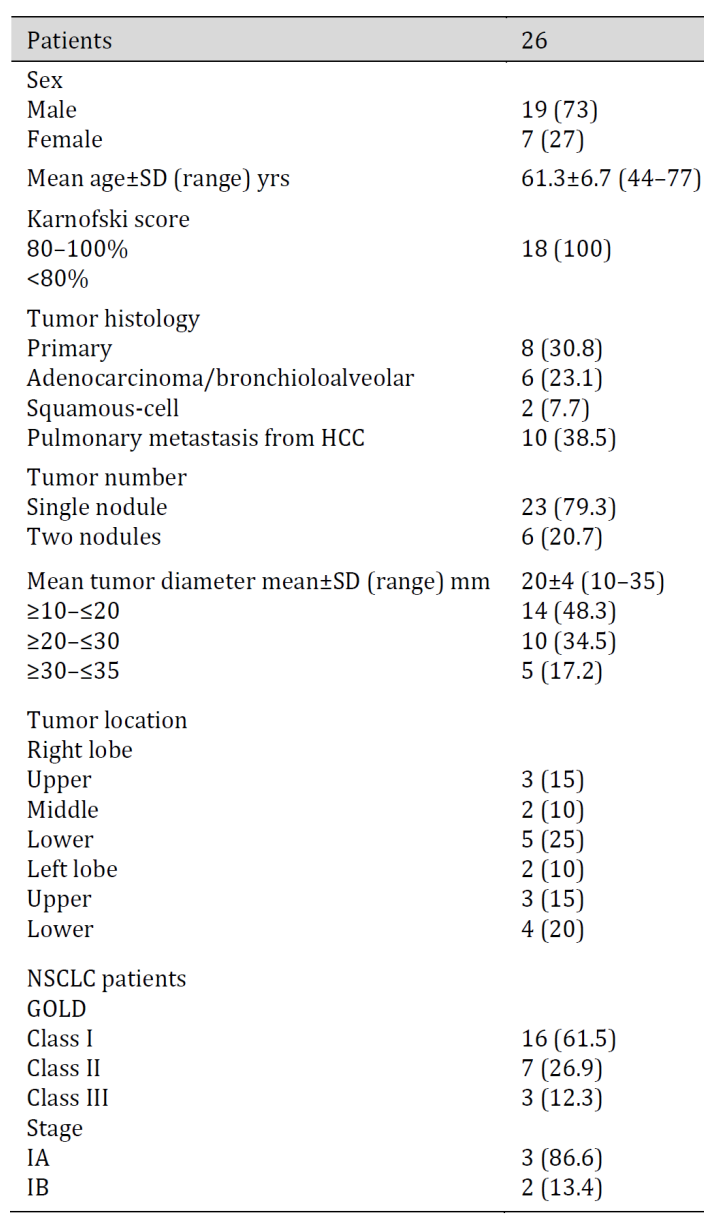

Fig. 1. Survival curves of NSCLC patients and pulmonary metastases from HCC after CT-PRFA showing the two-year overall and cancer-specific survival rate and one-year tumor-free survival rate.

Data analysis

Data are presented as mean \pm S.E.M. Statistical analyses were performed by using software (SPSS, version 9.0). The Kaplan-Meier method was used to estimate survival functions for patient mortality and local tumor progression rates, defined as any detectable tumor activity in the ablation zone. Median survival estimates were reported with 95\% confidence intervals (CIs) [23, 24]. Comparisons of survival functions were performed by using the log-rank test. $P<0.05$ was considered to indicate a statistically significant difference. Descriptive statistics were provided per tumor, but inferential statistics were limited to a perpatient level of analysis.

\section{Results}

Comparative efficacy of CT-PRFA for primary and metastatic lung cancers

Fourteen patients pathologically diagnosed with non-small cell lung cancer (NSCLC) and 12 patients with lung metastases from HCC were enrolled in the study. The patients 
Fig. 2. Effects of CT-PRFA on expression of selected miRNAs known to be critical regulators of lung cancer. MiRNA levels were quantified by Taqman real-time RT-PCR. Shown are data obtained from lung biopsy samples from all 26 patients prior to CT-PRFA therapy, 2 weeks following CT-PRFA, 7 tumor-free survivors 2 years following CT-PRFA, and non-survivors 2 year following CT-PRFA. ${ }^{*} P<0.05$, ${ }^{* *} P<0.01$ $\& \quad * * * P<0.001$ compared to Control (dashed line).
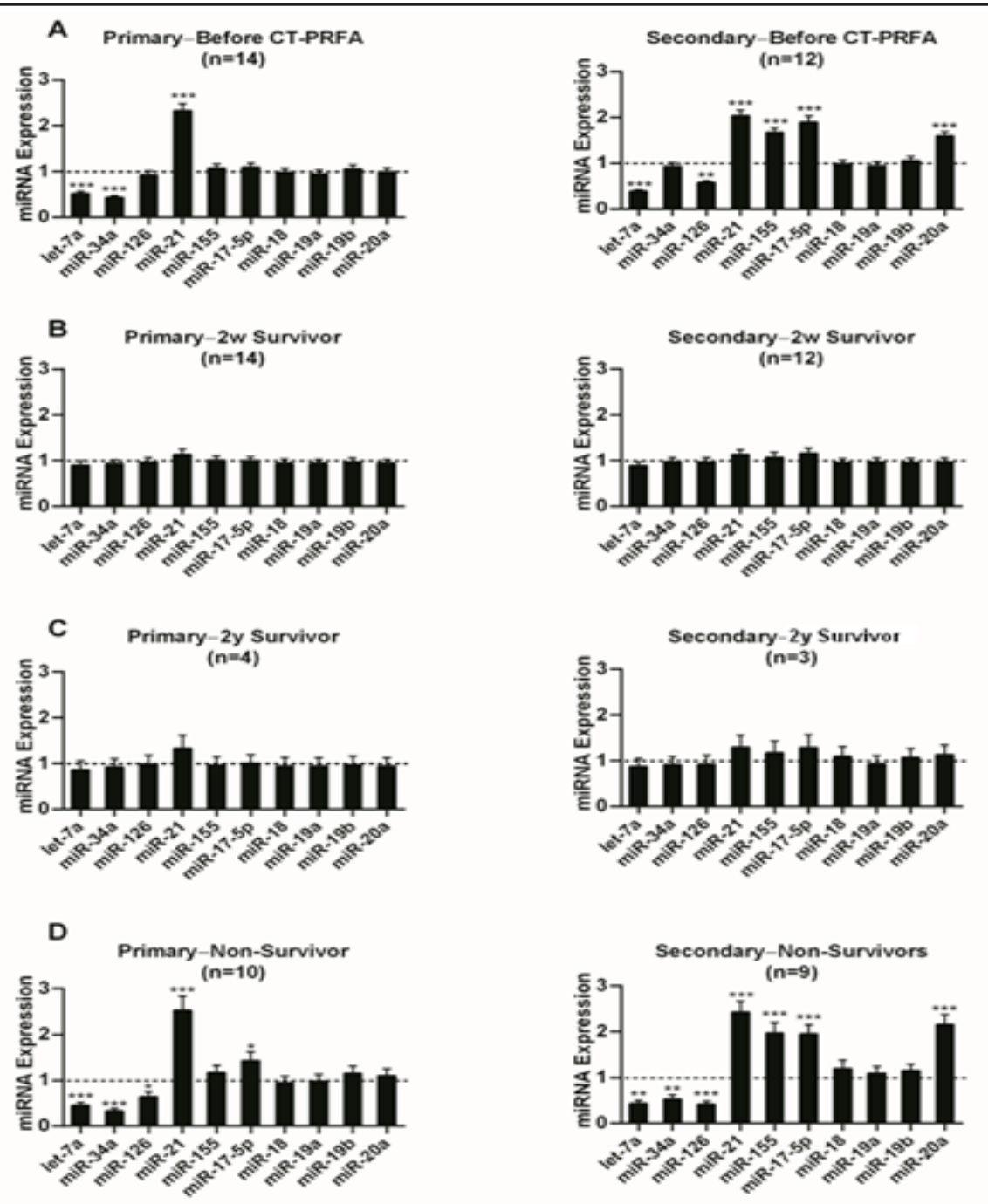

with primary NSCLC had no metastasis, and in patients with secondary lung cancer lung was the only site of metastasis. All 14 NSCLC patients had a single tumour. Nine of the 12 HCCmetastasis patients had a single tumour, whilst the other three patients had two tumors. Patient and tumor characteristics are summarised in Table 1.

All targeted tumors were treated in a single CT-PRFA session. None of the procedures had to be interrupted because of complications such as pneumothorax or hemorrhage. In 21 cases, a single electrode insertion was sufficient; two insertions were required in five cases. A total of 16 tumours were treated with umbrella-tip electrodes and spiral-tip electrodes were used for the remaining 10 tumors. None of the patients experienced severe pain.

The median follow-up was 15 months (range, 3-34 months) and no patient was lost to follow-up. During the follow-up period, only patient received systematic chemotherapy for adjuvant treatment of primary HCC, and the remaining patients received no anticancer therapy.

The rate of technique efficacy for primary tumors was 92.9\% (13 of 14) per procedure and $92.9 \%$ (13 of 14) per patient, with only one local tumor progression observed during follow-up 5 months after the treatment. The lung metastases were also treated with CT-PRFA. Treatment was successful in 11 out of 12 patients with only one failure $(91.7 \%$ successful rate). None of the procedures was associated with complications. In a whole, a total of 29 lung tumors were treated with CT-PRFA, and in 26 out of $29(89.7 \%)$ treated tumors the post-treatment CT findings revealed complete radiological ablation. 
Overall survival rate was $80.8 \%$ (95\% CI: 35\%, 95\%) at 2 years (Fig. 1A), and cancerspecific survival rate was $100 \%$ at 2 years (Fig. 1B). The tumor-free survival (Fig. 1C) was $69.2 \%$ at 1 year (95\% CI: $28 \%, 87 \%$ ) and $26.9 \%$ at 2 years (95\% CI: $5 \%, 56 \%$ ).

There were no major complications or deaths. Post-treatment CT revealed pneumothorax in five cases (15\%), but all were self-limiting and did not require drainage. The immediate complication rate was $31 \%$ and corresponded to five mild intrapulmonary hemorrhages, which did not require any further intervention and remained asymptomatic because they were minor and self-limited according to the small size of the observable alveolar condensation. The postprocedural complications consisted of only three cases of minor hemoptysis lasting less than two days without specific treatment. These three patients had normal coagulation parameters.

\section{Effects of CT-PRFA on expression of lung cancer-related miRNAs}

As already described, a number of miRNAs including let-7a, miR-34a, miR-21, miR-126, miR-155, miR-17-5p, miR-18, miR-19a, miR-19b, and miR-20a have been found deregulated in lungs with malignancies [22-40], indicating that these miRNAs are the key miRNAs in lung cancer. We therefore compared the expression levels of these miRNAs before CT-PRFA, 2-week tumor-free survivors after CT-PRFA, 2-year tumor-free survivors after CT-PRFA, and non-survivors after PRFA in the biopsy tissue from the area immediately surrounding the site of tumor ablation between primary and secondary lung cancers.

As depicted in Figure 2, there was a differential expression of miRNAs between primary and secondary lung cancer tissues. Let-7a and miR-34a were significantly downregulated, whereas miR-21 was markedly upregulated, with other miRNAs (miR-126, miR-155, miR17-5p, miR-18, miR-19a, miR-19b, and miR-20a) remaining unaltered, in primary lung cancer before PRFA (Fig. 2A). In metastatic lung cancer from HCC, let-7a and miR-126 levels were reduced whilst miR-21, miR-155 and miR-17-5p/miR-20a levels were increased (Fig. 2B). MiR-34a and other miRNAs were not significantly changed. Importantly, in both 2-week tumor-free survivors and 2-year tumor-free survivors, these deregulated miRNAs were completely or partially normalized in their expression levels by CT-PRFA in both primary and secondary lung cancers (Fig. 2C). In sharp contrast, in the tissue samples from 2-year non-survivors, the aberrantly expressed miRNAs remained deregulated (Fig. 2D).

\section{Discussion}

Ever since the first three clinical cases of CT-PRFA for lung cancer were described in 2000 [17], numerous studies have reported successful series of lung CT-PRFA procedures. Our small series suggests that lung CT-PRFA is a feasible therapeutic approach not only for NSCLC patients but also for patients with pulmonary metastases from HCC. The efficacy of CT-PRFA may be explained at least partially by the ability of this treatment to normalize the deregulated miRNAs that have been recognized to be critical to lung cancer. To our knowledge, our study presents the first investigation on the effects of CT-PRFA on miRNA expression in lung cancer tissues.

Thus far, many CT-PRFA studies have been conducted in patients NSCLCs who either could not undergo surgery because of comorbidities or advanced disease, or who refused to undergo surgery. Among these studies, six included patients with NSCLCs and metastatic lung disease originating from other primary tumors [13,44-51], three included only patients with colorectal metastases [52-54], two included patients with renal metastases $[55,56]$, and four studies included only patients with inoperable NSCLC [57-60]. Most of these studies included patients with stage I carcinoma, and numbers of patients in each of the above series ranged from 18 to 153.

In our series, the 2-year survival rate was $80.8 \%$, consistent with a recent study showing $71.4 \%$ survival rate [61] and a meta-analysis of 17 studies with a 1-, 2-, and 3-year survival rates of $63 \%-85 \%, 55 \%-65 \%$, and $15 \%-46 \%$, respectively [62]. Our cancer-specific survival 
rate of $100 \%$ at 2 years demonstrated that death occurred due to causes other than cancer, underlining simultaneously the fragility of the population and the efficacy of the treatment. This result was also in line with previous studies in NSCLC patients [56, 59]. A recent study conducted by Simon et al. [44] presented data on long-term survival rates up to five years for primary (both early and advanced stage) and metastatic lesions and disease free survival rates and progression free intervals for lesions measuring $<3 \mathrm{~cm}$ and $>3 \mathrm{~cm}$. The survival rates from colorectal metastases are promising in this study; however, because most of these patients received neoadjuvant and/or adjuvant chemotherapy, the sole effect of RFA cannot be reliably estimated. Hiraki et al. [58] reported the longest survival rates for patients with metastases, while Pennathur et al. [60] reported the highest 1-year survival rate for patients with stage 1 carcinoma.

One notable finding in our study is the ability of CT-PRFA to alter miRNA expression in lung tissues surrounding the site of tumor ablation, or more specifically to normalize the deregulated miRNAs in lung cancer. Before PRFA, the deregulated miRNAs appear to be different between primary and secondary lung cancers: let-7a and miR-34a were downregulated whereas miR-21 was upregulated in the tissues with primary tumors, and let-7a and miR-126 levels were downregulated whereas miR-21, miR-155 and miR-17-5p/ miR-20b levels were upregulated in the tissues with secondary tumors. These abnormal alterations of expression of the key miRNAs were normalized by CT-PRFA. Probably most intriguing is the observation that CT-PRFA failed to normalize the deregulated miRNAs in the non-survivors. These findings provide an explanation for our clinical data and suggest that changes of expression of these miRNAs may contribute to the molecular mechanisms for the efficacy of CT-PRFA.

It should be noted that our study has important limitations. Our results do not justify strong statements regarding efficacy because of the small sample size, as attested by the relatively large 95\% CIs noted in survival rates, and because of the limited follow-up time in most of the patients. Additionally, because of the limited size of the biopsy and ethical and technical obstacles, we were unable to conduct experiments on protein levels and functions of the target genes for the miRNAs of our interest. Furthermore, we only studied a set of selected miRNAs and the possible roles of other miRNAs were not investigated. Nonetheless, these miRNAs have been previously validated for their target genes and roles in lung cancer, and on the basis of these published data, we are able to use our miRNA results to explain our clinical observations. Yet we should still admit that our miRNA data are merely suggestive of the potential molecular mechanism for CT-PRFA therapy of lung cancer.

In conclusion, we have in this study provided combined clinical observations and fundamental investigations on the therapeutic efficacy of CT-PRFA for both primary and HCC-metastatic lung cancers, and the associated changes of expression of some key miRNAs as well. Based on our results, CT-PRFA is an effective therapeutic option with promising results when applied to a highly selective group of patients with isolated primary NSCLCs and secondary lung tumors from HCC. The efficacy of CT-PRFA may be related to its ability to normalize deregulated expression of miRNAs: upregulating tumor suppressor miRNAs and downregulating oncomiRs.

\section{Conflicts of Interest}

The authors declare no conflicts of interest for this study.

\section{References}

1 Smith RA, Glynn TJ: Epidemiology of lung cancer. Radiol Clin N Am 2000;38:453-470.

-2 Fry WA, Phillips JL, Menck HR: Ten-year survey of lung cancer treatment and survival in hospitals in the United States: a national cancer data base report. Cancer 1999;86:1867-1876.

3 Spiro SG, Porter JC: Lung cancer-where are we today?Am J Respir Crit Care Med 2002;166:1166-1196. 
Hu/Zhang/Liu/Wu/Ni: CT-PRFA for Primary Lung Cancer

4 Penna C, Nordlinger B: Colorectal metastasis (liver and lung). Surg Clin North Am 2002;82:1075-1090.

-5 Fernando HC, De Hoyos A, Landreneau RJ, Gilbert S, Gooding WE, Buenaventura PO, Christie NA, Belani C, Luketich JD: Radiofrequency ablation for the treatment of non-small lung cancer in marginal surgical candidates. J Thorac Cardiovasc Surg 2005;129:639-44.

-6 Herrera LJ, Fernando HC, Perry Y, Gooding WE, Buenaventura PO, Christie NA, Luketich JD: Radiofrequency ablation of pulmonary malignant tumors in nonsurgical candidates. J Thorac Cardiovasc Surg 2003;125:929-937.

7 Spira A, Ettinger DS: Multidisciplinary management of lung cancer. N Engl J Med 2004;350:379-392.

8 Marino P, Preatoni A, Cantoni A: Randomized trials of radiotherapy in stage IIIa and IIIb non-small cell lung cancer: a meta-analysis. Cancer 1995;176:593-601.

9 Siperstein A, Gotomirski A: History and technological aspects of radiofrequency thermoablation. Cancer J 2000;6:S293-301.

10 McGahan JP, Dodd III GD: Radiofrequency ablation of the liver: current status. Am J Roentgenol 2001;176:3-16.

-11 Dupuy DE, Zagoria RJ, Akerley W, Mayo-Smith WW, Kavanagh PV, Safran H: Percutaneous radiofrequency ablation of malignancies in the lung. AJR Am J Roentgenol 2000;174:57-59.

12 Suh RD, Wallace AB, Sheehan RE, Heinze SB, Goldin JG: Unresectable pulmonary malignancies: CT-guided percutaneous radiofrequency ablation - preliminary results. Radiology 2003;229:821-829.

-13 Lee JM, Jin GY, Goldberg SN, Lee YC, Chung GH, Han YM, Lee SY, Kim CS: Percutaneous radiofrequency ablation for inoperable non-small cell lung cancer and metastases: preliminary report. Radiology 2004;230:125-134.

14 Gadaleta C, Mattioli V, Colucci G, Cramarossa A, Lorusso V, Canniello E, Timurian A, Ranieri G, Fiorentini G, De Lena M, Catino A: Radiofrequency ablation of 40 lung neoplasms: preliminary results. AJR Am J Roentgenol 2004;183:361-368.

15 Nishida T, Inoue K, Kawata Y, Izumi N, Nishiyama N, Kinoshita H, Matsuoka T, Toyoshima M: Percutaneous radiofrequency ablation of lung neoplasms: A minimally invasive strategy for inoperable patients. J Am Coll Surg 2002;195:426-430.

-16 Marasso A, Bernardi V, Gai R, Gallo E, Massaglia GM, Onoscuri M, Cardaci SB: Radiofrequency resection of bronchial tumors in combination with cryotherapy: evaluation of a new technique. Thorax 1998;53:106109.

17 Schoellnast H, Deodhar A, Hsu M, Moskowitz C, Nehmeh SA, Thornton RH, Sofocleous CT, Alago W Jr, Downey RJ, Azzoli CG, Rosenzweig KE, Solomon SB: Recurrent non-small cell lung cancer: evaluation of CTguided radiofrequency ablation as salvage therapy. Acta Radiol 2012;53:893-899.

18 Ding JH, Chua TC, Glenn D, Morris DL: Feasibility of ablation as an alternative to surgical metastasectomy in patients with unresectable sarcoma pulmonary metastases. Interact Cardiovasc Thorac Surg 2009;9:10511053.

19 Hachisuka Y, Uomoto M, Fujisawa T, Mogami H: First reported case of lung metastasis from hepatocellular carcinoma successfully treated by ultrasound-guided radiofrequency ablation using ultrasonic contrast agent. Gan To Kagaku Ryoho 2009;36:2657-2659.

20 Hiraki T, Yamakado K, Ikeda O, Matsuoka T, Kaminou T, Yamagami T, Gobara H, Mimura H, Kawanaka K, Takeda K, Yamashita Y, Inoue Y, Ogawa T, Nishimura T, Kanazawa S: Percutaneous radiofrequency ablation for pulmonary metastases from hepatocellular carcinoma: results of a multicenter study in Japan. J Vasc Interv Radiol 2011;22:741-748.

21 Hiraki T, Gobara H, Mimura H, Sano Y, Tsuda T, Iguchi T, Fujiwara H, Kishi R, Matsui Y, Kanazawa S: Does tumor type affect local control by radiofrequency ablation in the lungs? Eur J Radiol 2010;74:136-141.

22 Zhao B, Han H, Chen J, Zhang Z, Li S, Fang F, Zheng Q, Ma Y, Zhang J, Wu N, Yang Y: MicroRNA let-7c inhibits migration and invasion of human non-small cell lung cancer by targeting ITGB3 and MAP4K3. Cancer Lett 2014;342:43-51.

23 Capodanno A, Boldrini L, Proietti A, Alì G, Pelliccioni S, Niccoli C, D'Incecco A, Cappuzzo F, Chella A, Lucchi M, Mussi A, Fontanini G: Let-7g and miR-21 expression in non-small cell lung cancer: Correlation with clinicopathological and molecular features. Int J Oncol. 2013;43:765-774.

-24 Jusufović E, Rijavec M, Keser D, Korošec P, Sodja E, Iljazović E, Radojević Z, Košnik M: Let-7b and miR-126 are down-regulated in tumor tissue and correlate with microvessel density and survival outcomes in nonsmall-cell lung cancer. PLoS One 2012;7:e45577. 
Hu/Zhang/Liu/Wu/Ni: CT-PRFA for Primary Lung Cancer

25 Wang YY, Ren T, Cai YY, He XY: MicroRNA let-7a inhibits the proliferation and invasion of nonsmall cell lung cancer cell line 95D by regulating K-Ras and HMGA2 gene expression. Cancer Biother Radiopharm 2013;28:131-137.

26 Yanaihara N, Caplen N, Bowman E, Seike M, Kumamoto K, Yi M, Stephens RM, Okamoto A, Yokota J, Tanaka T, Calin GA, Liu CG, Croce CM, Harris CC: Unique microRNA molecular profiles in lung cancer diagnosis and prognosis. Cancer Cell 2006;9:189-198.

27 Yu SL, Chen HY, Chang GC, Chen CY, Chen HW, Singh S, Cheng CL, Yu CJ, Lee YC, Chen HS, Su TJ, Chiang CC, Li HN, Hong QS, Su HY, Chen CC, Chen WJ, Liu CC, Chan WK, Chen WJ, Li KC, Chen JJ, Yang PC: MicroRNA signature predicts survival and relapse in lung cancer. Cancer Cell 2008;13:48-57.

28 Takamizawa J, Konishi H, Yanagisawa K, Tomida S, Osada H, Endoh H, Harano T, Yatabe Y, Nagino M, Nimura Y, Mitsudomi T, Takahashi T: Reduced expression of the let-7 microRNAs in human lung cancers in association with shortened postoperative survival. Cancer Res 2004;64:3753-3756.

29 Yang J, Lan H, Huang X, Liu B, Tong Y: MicroRNA-126 inhibits tumor cell growth and its expression level correlates with poor survival in non-small cell lung cancer patients. PLoS One 2012;7:e42978.

-30 Liu B, Peng XC, Zheng XL, Wang J, Qin YW: MiR-126 restoration down-regulate VEGF and inhibit the growth of lung cancer cell lines in vitro and in vivo. Lung Cancer 2009;66:169-175.

- 31 Crawford M, Brawner E, Batte K, Yu L, Hunter MG, Otterson GA, Nuovo G, Marsh CB, Nana-Sinkam SP: MicroRNA-126 inhibits invasion in non-small cell lung carcinoma cell lines. Biochem Biophys Res Commun 2008;373:607-612.

-32 Wang Z, Chen Z, Gao Y, Li N, Li B, Tan F, Tan X, Lu N, Sun Y, Sun J, Sun N, He J: DNA hypermethylation of microRNA-34b/c has prognostic value for stage I non-small cell lung cancer. Cancer Biol Ther 2011;11:490-496.

33 Wang LG, Ni Y, Su BH, Mu XR, Shen HC, Du JJ: MicroRNA-34b functions as a tumor suppressor and acts as a nodal point in the feedback loop with Met. Int J Oncol 2013;42:957-962.

34 Tanaka N, Toyooka S, Soh J, Kubo T, Yamamoto H, Maki Y, Muraoka T, Shien K, Furukawa M, Ueno T, Asano H, Tsukuda K, Aoe K, Miyoshi S: Frequent methylation and oncogenic role of microRNA-34b/c in small-cell lung cancer. Lung Cancer 2012;76:32-38.

-35 Gallardo E, Navarro A, Viñolas N, Marrades RM, Diaz T, Gel B, Quera A, Bandres E, Garcia-Foncillas J, Ramirez J, Monzo M: miR-34a as a prognostic marker of relapse in surgically resected non-small-cell lung cancer. Carcinogenesis 2009;30:1903-9190.

-36 Raponi M, Dossey L, Jatkoe T, Wu X, Chen G, Fan H, Beer DG: MicroRNA classifiers for predicting prognosis of squamous cell lung cancer. Cancer Res 2009;69:5776-6783.

37 Saito M, Schetter AJ, Mollerup S, Kohno T, Skaug V, Bowman ED, Mathé EA, Takenoshita S, Yokota J, Haugen A, Harris CC: The association of microRNA expression with prognosis and progression in early stage, non small cell lung adenocarcinoma: a retrospective analysis of three cohorts. Clin Cancer Res 2011;17:1875-1882.

- 38 Liu ZL, Wang H, Liu J, Wang ZX: MicroRNA-21 (miR-21) expression promotes growth, metastasis, and chemo- or radioresistance in non-small celllung cancer cells by targeting PTEN. Mol Cell Biochem 2013;372:35-45.

39 Yang M, Shen H, Qiu C, Ni Y, Wang L, Dong W, Liao Y, Du J: High expression of miR-21 and miR-155 predicts recurrence and unfavourable survival in non-small cell lungcancer. Eur J Cancer 2013;49:604-615.

-40 Hayashita Y, Osada H, Tatematsu Y, Yamada H, Yanagisawa K, Tomida S, Yatabe Y, Kawahara K, Sekido Y, Takahashi T: A polycistronic microRNA cluster, miR-17-92, is overexpressed in human lung cancers and enhances cell proliferation. Cancer Res 2005;65:9628-9632.

-41 Rossi S, Dore R, Cascina A, Vespro V, Garbagnati F, Rosa L, Ravetta V, Azzaretti A, Di Tolla P, Orlandoni G, Pozzi E: Percutaneous computed tomography-guided radiofrequency thermal ablation of small unresectable lung tumours. Eur Respir J 2006;27:556-63.

42 Mountain CF, Dresler CM: Regional lymph node classification for lung cancer staging. Chest 1997;111:1718-1723.

43 Pauwels RA, Buist AS, Ma P, Jenkins CR, Hurd SS, GOLD Scientific Committee: Global strategy for the diagnosis, management, and prevention of chronic obstructive pulmonary disease: National Heart, Lung, and Blood Institute and World Health Organization Global Initiative for Chronic Obstructive Lung Disease (GOLD): executive summary. Respir Care 2001;46:798-825. 
Hu/Zhang/Liu/Wu/Ni: CT-PRFA for Primary Lung Cancer

44 Simon CJ, Dupuy DE, DiPetrillo TA, Safran HP, Grieco CA, Ng T, Mayo-Smith WW: Pulmonary radiofrequency ablation: long-term safety and efficacy in 153 patients. Radiology 2007;243:268-275.

45 Thanos L, Mylona S, Pomoni M, Athanassiadi K, Theakos N, Zoganas L, Batakis N: Percutaneous radiofrequency thermal ablation of primary and metastatic lung tumors. Eur J Cardiothorac Surg 2006;30:797-800.

46 Ambrogi MC, Lucchi M, Dini P, Melfi F, Fontanini G, Faviana P, Fanucchi O, Mussi A: Percutaneous radiofrequency ablation of lung tumours: results in the mid-term. Eur J Cardiothorac Surg 2006;30:177183.

47 Thanos L, Mylona S, Pomoni M, Athanassiadi K, Theakos N, Zoganas L, Batakis N: Percutaneous radiofrequency thermal ablation of primary and metastatic lung tumors. Eur J Cardiothorac Surg 2006;30:797-800.

48 Hublet A, Wijtenburg E, Lismonde M, Thomas T, Majois F, de Lovinfosse S, Delaunoit T, Mitine C, Vermonden J, Nicaise G, Van Ruyssevelt P: Feasibility of percutaneous radiofrequency ablation for pulmonary malignancies in the hands of the surgeon. Acta Chir Belg 2010;110:267-271.

49 Schoellnast H, Larson SM, Nehmeh SA, Carrasquillo JA, Thornton RH, Solomon SB: Radiofrequency ablation of non-small-cell carcinoma of the lung under real-time FDG PET CT guidance. Cardiovasc Intervent Radiol 2011;34 Suppl 2:S182-S185.

-50 Okuma T, Matsuoka T, Yamamoto A, Oyama Y, Hamamoto S, Toyoshima M, Nakamura K, Miki Y: Determinants of local progression after computed tomography-guided percutaneous radiofrequency ablation for unresectable lung tumors: 9-year experience in a single institution. Cardiovasc Intervent Radiol 2010;33:787-793.

-51 Tanabe T, Koizumi T, Tsushima K, Ito M, Kanda S, Kobayashi T, Yasuo M, Yamazaki Y, Kubo K, Honda T, Kondo R, Yoshida K: Comparative study of three different catheters for CT imaging-bronchoscopyguided radiofrequency ablation as a potential and novel interventional therapy for lung cancer. Chest 2010;137:890-897.

-52 Hiraki T, Gobara H, Iishi T, Sano Y, Iguchi T, Fujiwara H, Tajiri N, Sakurai J, Date H, Mimura H, Kanazawa S: Percutaneous radiofrequency ablation for pulmonary metastases from colorectal cancer: midterm results in 27 patients. J Vasc Interv Radiol 2007;18:1264-1269.

53 Yamakado K, Hase S, Matsuoka T, Tanigawa N, Nakatsuka A, Takaki H, Takao M, Inoue Y, Kanazawa S, Inoue Y, Sawada S, Kusunoki M, Takeda K: Radiofrequency ablation for the treatment of unresectable lung metastases in patients with colorectal cancer: A multicenter study in Japan. J Vasc Interv Radiol 2007;18:393-398.

54 King J, Glenn D, Clark W, Zhao J, Steinke K, Clingan P, Morris DL: Percutaneous radiofrequency ablation of pulmonary metastases in patients with colorectal cancer. Br J Surg 2004;91:217-223.

-55 Shu Yan Huo A, Lawson Morris D, King J, Glenn D: Use of percutaneous radiofrequency ablation in pulmonary metastases from renal cell carcinoma. Ann Surg Oncol 2009;16:3169-3175.

-56 Soga N, Yamakado K, Gohara H, Takaki H, Hiraki T, Yamada T, Arima K, Takeda K, Kanazawa S, Sugimura Y: Percutaneous radiofrequency ablation for unresectable pulmonary metastases from renal cell carcinoma. BJU Int 2009;104:790-4.

-57 Fernando HC, De Hoyos A, Landreneau RJ, Gilbert S, Gooding WE, Buenaventura PO, Christie NA, Belani C, Luketich JD: Radiofrequency ablation for the treatment of non-small cell lung cancer in marginal surgical candidates. J Thorac Cardiovasc Surg 2005;129:639-644.

-58 Hiraki T, Gobara H, Iishi T, Sano Y, Iguchi T, Fujiwara H, Tajiri N, Sakurai J, Date H, Mimura H, Kanazawa S: Percutaneous radiofrequency ablation for clinical stage I non-small cell lung cancer: Results in 20 nonsurgical candidates. J Thorac Cardiovasc Surg 2007;134:1306-1312.

59 Ambrogi MC, Dini P, Melfi F, Mussi A: Radiofrequency ablation of inoperable non-small cell lung cancer. J Thorac Oncol 2007;2:S2-3.

60 Pennathur A, Luketich JD, Abbas G, Chen M, Fernando HC, Gooding WE, Schuchert MJ, Gilbert S, Christie NA, Landreneau RJ: Radiofrequency ablation for the treatment of stage I non-small cell lung cancer in high-risk patients. Thorac Cardiovasc Surg 2007;134:857-864.

61 Hess A, Palussière J, Goyers JF, Guth A, Aupérin A, de Baère T: Pulmonary radiofrequency ablation in patients with a single lung: feasibility, efficacy, and tolerance. Radiology 2011;258:635-642.

62 Zhu JC, Yan TD, Morris DL: A systematic review of radiofrequency ablation for lung tumors. Ann Surg Oncol 2008;15:765-1774. 